Reprod. Nutr. Dévelop., 1983, 23 (6), 1019-1027.

\title{
Influence of daily feeding within a limited time on weight, digestive transit and cholesterol turnover in adult rats
}

\author{
T. MAGOT, F. CHEVALLIER
}

Laboratoire de Physiologie de la Nutrition (*), Université de Paris-Sud, Bâtiment 447, 91405 Orsay Cedex, France.

Summary. Rats were trained to a single daily meal of $15 \mathrm{~g}$ between 6 and $9 \mathrm{a} . \mathrm{m}$. In fact, they only ingested an average of $14.4 \mathrm{~g}$ with $90 \%$ during the first hour. This value defined the average volumic capacity of the full stomach of our rats. Body weight stabilized rapidly at $402 \pm 2 \mathrm{~g}$; this value was obtained before with the same daily intake when the diet was available during the day according to the classical spontaneous rhythm. The restriction used did not alter the number of fecal pellets. On the other hand, coprophagy was reduced $(29 \%$ of total pellets instead of $41 \%$ ). The rhythm of fecal elimination was the same in restricted and control rats. These results suggested the role of light variation as a fecal elimination synchronizer, a role imputed previously to dietary intake. Lastly, rat gastric emptying occurred according to a monoexponential function whose $t_{1 / 2}$ was around 4.5 hours.

We also studied the cholesterol system using the isotopic equilibrium method. Mean daily flow values of different cholesterol turnover processes were nearly the same as those of ad libitum-fed rats, but circadian variations of cholesterol synthesis were more marked.

\section{Introduction.}

Plasma cholesterol is the central compartment of the cholesterol system. Two types of cholesterol enter the plasma : dietary cholesterol, after it is absorbed by the intestine, and cholesterol synthesized by various organs. In order to describe the role played by each class of lipoprotein, in the flow of these two types of cholesterol, dietary or synthetic cholesterol must be labelled. This description is facilitated if the labels are introduced at exactly determined times. Thus, to avoid the usual distribution of solid-food intake to rats fed ad libitum, we conditioned some rats to ingest a constant weight of food between 6 and 9 a.m. or, in fact, as will be shown, between 6 and 7 a.m. The effect of this time 
restriction has already been studied in relation to carbohydrate (Leveille and Chakrabarty, 1967 ; Fuller and Diller, 1970 ; Kaul and Berdanier, 1977 ; Blaizot, 1979) or fatty acid (Leveille and Ohea, 1967 ; Fuller and Diller, 1970) metabolism. The present preliminary study analyzes in rats the various effects of our experimental conditions on different physiological characteristics (weight, digestive transit) and on cholesterol turnover.

\section{Material and methods.}

\section{Biological material and experimental conditions.}

We used adult male rats of the Wistar strain given a semi-synthetic diet since weaning; the diet composition has been precisely described in previous studies (Mathé et al., 1977) : sucrose $53 \%$, casein $23 \%$, lard $8 \%$. The light cycle was composed of alternating periods of darkness and light (darkness from $8: 30$ p.m. to 7.30 a.m. and light from $8: 30$ a.m. to $7: 30$ p.m.) separated by a dawn and a twilight, each lasting $1 \mathrm{~h}$ (Chevallier et al., 1974). When the rats weighed about $400 \mathrm{~g}$, they were put into individual cages with a latticed floor so that they could eat $15 \mathrm{~g}$ of food in a single solid daily meal between 6 and 9 a.m. ; water was available ad libitum throughout the day.

The meal was distributed automatically by a mechanical apparatus. Except for a few rats which were discarded, the weight of the rats was little perturbed by this restriction and it stabilized. After one month of this treatment, we considered that the rats had been conditioned; the mean weight of the 320 treated rats was $402 \pm 2 \mathrm{~g}$.

\section{Experimental protocol.}

a) Measurement of some physiological characteristics.

1. - The chronology of food intake was determined in 18 rats by measuring the weight of non-ingested food, hour by hour, during the $3 \mathrm{~h}$ it was available.

2. - The weight profile of restricted rats was studied with $80,24,44,4,3,4$, and 9 rats after $1,1.5,2,3,5,9$ and 13 months, respectively. In parallel, we noted changes in the weight of 18 control rats fed ad libitum.

3. - The rate of stomachal emptying was determined in rats that ingested $15 \mathrm{~g}$ of food containing $4-{ }^{14} \mathrm{C}$-cholesterol $(87300 \mathrm{dpm} / \mathrm{mg})$. These rats were killed $4,6,17$ and $28 \mathrm{~h}$ after the beginning of intake and their stomachal contents were sampled by lots of 6 ( 2 lots per time interval) before their radioactivity was measured ; the results obtained were thus the mean of 6 experimental rats.

4. - The rhythm of fecal pellet elimination and of coprophagy was determined using 6 groups of 4 rats each. We counted the number of fecal pellets in the stomach and the number of those found on the bottom of the cage at different times of the circadian cycle $(2,6$ and 10 a.m. ; 2, 6 and 10 p.m.). The fecal pellet count was too approximative to calculate the SEM.

b) Isotopic equilibrium technique.

This technique, used to determine the flows of the main processes of cholesterol turnover (Chevallier and Lutton, 1966 ; Lutton and Chevallier, 1972), 
was applied to a group of 6 control rats fed ad libitum (these rats had been used in another experiment ; see Magot et al., 1983) and to a group of 8 rats submitted to the feeding rhythm used in this study. After 2 months of conditioning, the different rats were given a daily sub-cutaneous injection of ${ }^{3} \mathrm{H}$-cholesterol $(1 \mu \mathrm{Ci})$ and a diet containing ${ }^{14} \mathrm{C}$-cholesterol $(25 \mu \mathrm{Ci} / 10 \mathrm{~kg})$. The two labels were administered simultaneously during 2 months. Four restricted rats and the controls were killed at $9: 30 \mathrm{a} . \mathrm{m}$. and the other 4 restricted rats at $5: 30 \mathrm{p} . \mathrm{m}$. We sampled the plasma and red cells as well as the liver and various parts of the digestive tract. Urine and feces were collected during the last 4 weeks. The sterol content of each sample was analyzed and its radioactivity measured. Once we knew the radioactivity of the neutral sterols and fecal bile acids and the specific radioactivity of plasma and dietary cholesterol, we calculated the daily flows (in $\mathrm{mg} /$ day) of absorption, internal secretion, fecal external secretion, fecal cholesterol excretion and that of bile acid production. Internal secretion corresponds to the cholesterol biosynthesized in the organs and diverted into the plasma and external secretion to that biosynthesized by the digestive tract and directly eliminated in the feces. Fecal cholesterol excretion corresponds to the transfer of plasma cholesterol into the lumen (Chevallier and Lutton, 1966).

\section{Chemical and isotopic techniques.}

The techniques for isolating free and esterified cholesterol from various samples and the measurement of their specific radioactivity have already been described (Mathé and Chevallier, 1979). They include the extraction of organ lipids by boiling alcohol in a Soxhlet apparatus, cellulose filtration, fractionation of the lipids into esterified and free sterols by silicic acid chromatography, precipitation of the unsaponifiable sterols using digitonin, washing the complex, and finally its breakdown by pyridine.

Radioactivity was measured with a scintillation counter. The cholesterol masses were measured by colorimetric assay according to the method of Lieberman-Burchard.

\section{Results and discussion.}

\section{Physiological characteristics.}

Before discussing the various characteristics studied in rats restricted to a single food intake of $3 \mathrm{~h}$, we wish to make an important remark concerning the chronology of this intake. During the first hour that the food was available, the rats ingested a mean of $13.3 \pm 0.6 \mathrm{~g}$ or almost $90 \%$ of the daily amount available. During the second hour they ingested $0.9 \pm 0.3 \mathrm{~g}(6 \%)$ and during the

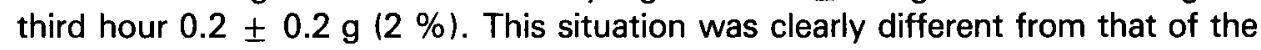
ad libitum fed rats whose feeding was much more discontinuous (Lutton and Chevallier, 1973), i.e. $60 \%$ during the second part of the dark phase (1 a.m. to 8 a.m.), almost $30 \%$ at the very beginning of the night $(6$ p.m. to 9 p.m.) and $10 \%$ in the afternoon (12 noon to 6 p.m.). Moreover, the total amount of food ingested during the $3 \mathrm{~h}$ it was available was not $15 \mathrm{~g}$ but only $14.4 \mathrm{~g}$. The volumic capacity of the stomach was probably the main element in this restriction. To 
check this supposition, we measured the amount of food ingested in 15 rats when it was available with the same time restriction but ad libitum. This mean amount was $17.5 \pm 0.5 \mathrm{~g}$ and probably represents the maximal volumic capacity of the rat stomach. It is evident that none of the experimental rats having a maximal capacity higher than $15 \mathrm{~g}$ could use it to advantage because they were only given $15 \mathrm{~g}$ of food; this explains why mean intake was only $14.4 \mathrm{~g}$.

a) Weight profile. - At 17 months of age, the ad libitum-fed rats had not finished growth (fig. 1). On the other hand, except at 9 months (represented by only 4 rats), the weight of the restricted rats remained constant at about $400 \mathrm{~g}$ for 13 months after restriction began. This effect was identical to the one observed when the same diet was only restricted quantitatively with no time limit on food intake (Chevallier et al., 1975). This observation suggests that rat weight is defined by the food available whether a feeding rhythm is imposed or not. The daily chronology of food intake would thus have little effect on a given physiological equilibrium in rat. This hypothesis must be confirmed by using other feeding schedules for food intake than the one we employed.

b) Digestive transit. - Figure 2 shows the radioactivity of ${ }^{14} \mathrm{C}$-cholesterol measured in the stomachal contents for $28 \mathrm{~h}$ after the labelled diet was ingested $(15 \mathrm{~g})$. Considering the radioactivity present per $\mathrm{g}$ of ingested diet, we calculated the mass, $Q$ (in $\mathrm{g}$ ), of the diet remaining in the stomach at each time $t$ (in hours). This mass decreased monoexponentially according to the equation : $\mathrm{Q}=15 \mathrm{e}^{-0.15 \mathrm{t}}$.
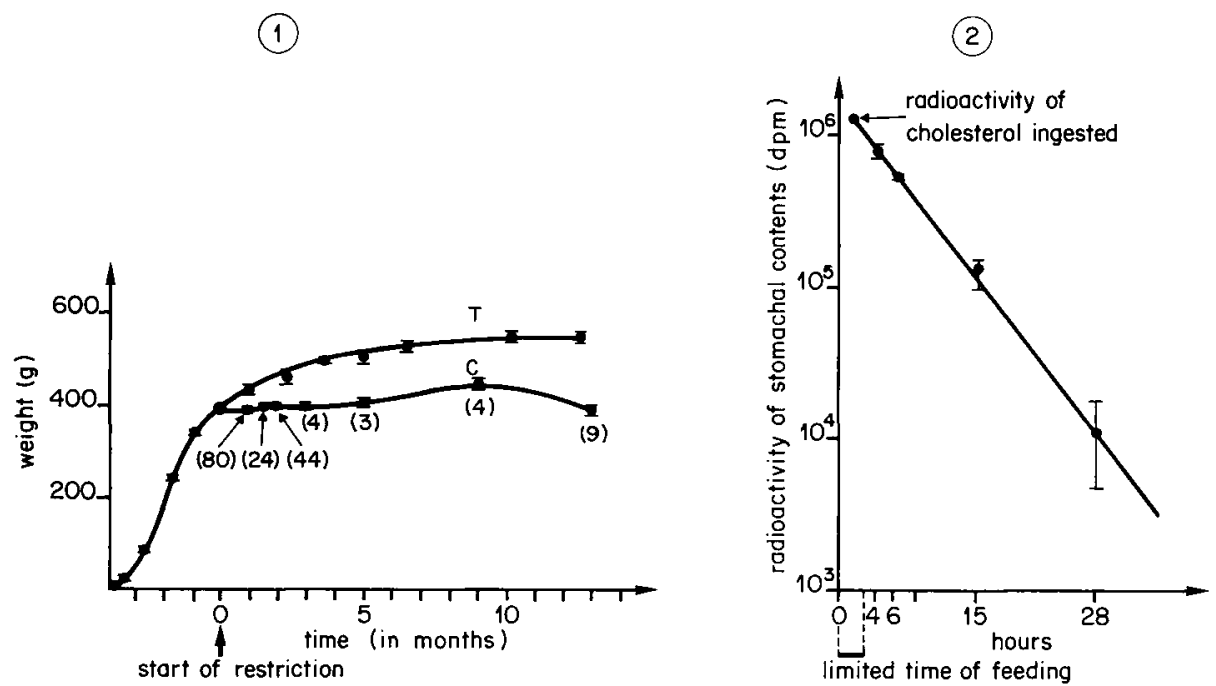

FIG. 1. - Profile of the mean weight ( $\pm \mathrm{SEM})$ of 12 ad libitum-fed rats $(\mathrm{T})$ and of rats ingesting a single daily meal (C). The numbers in parentheses are the number of experimental rats used.

FIG. 2. - Profile of the mean radioactivity $t$ SEM) of the stomachal contents of rats eating a single meal with labelled cholesterol $\left(1.31 .10^{6} \mathrm{dpm}\right)$. Twelve rats were used in each experiment. The rats were killed by lots of 6 each. 
The half-decay time $\left(t_{1 / 2}\right)$ was about $4 \mathrm{~h}$. Similar modes of stomachal content emptying have already been observed in man (Hunt and Spurell, 1951) as well as in pig, if the results are expressed in amount of dry matter (Rérat and Lougnon, 1963) and not in total quantity (Laplace and Tomassone, 1970).

Figure 3 shows the number of fecal pellets found in the stomach of rats killed at different times of the circadian cycle. It has been shown that these stomach pellets are rapidly evacuated into the intestine (Lutton et Chevallier, 1973). Moreover, if we apply to pellets in rat stomach a clearance rate equal to that defined above for food $(50 \%$ in $4 \mathrm{~h})$, the experimental result is close to the calculated theoretical value (e.g. see points $\mathrm{A}$ and $\mathrm{B}$ on figure 3 ). It follows that the pellets counted between 2 and 6 a.m. were only the residues of those present at $10 \mathrm{p} . \mathrm{m}$. When the analysis is extended to the duration of the circadian cycle, it shows that coprophagy occurred mainly between 6 and 10 a.m. (2.25 pellets), 10 a.m. and 2 p.m. $(1.75$ pellets) and 6 and 10 p.m. (2.25 pellets) and that it involved a total of about 6 pellets. Compared to control rats ingesting the same diet, the experimental rats showed less coprophagy (6 pellets instead of 12.9) and it was dispersed in time (Lutton and Chevallier, 1973). In fact, the control rats ingested $3 / 4$ of the pellets between 5 and 8 a.m.

The mean number of pellets found on the bottom of the cages of 24 rats after eight $24-\mathrm{h}$ measurements was $14.4 \pm 0.4$ pellets per day per rat. The total daily amount of pellets (ingested and non-ingested) eliminated was thus 20.4. Taking into account the previous results on control rats $(30.5$ pellets eliminated per day for a daily intake of $20 \mathrm{~g}$ ), this value was close to the one calculated

(3)

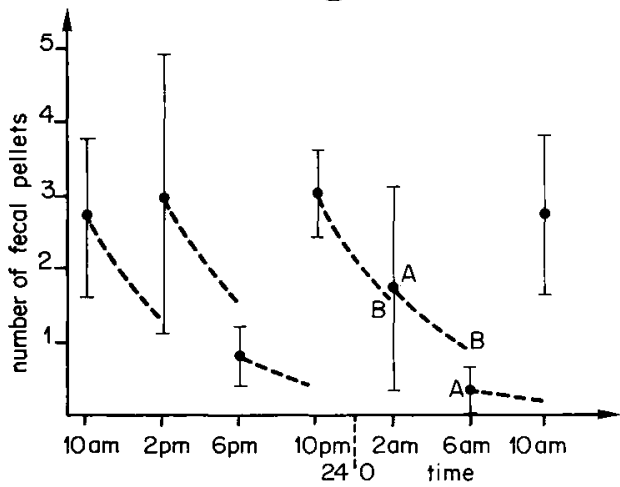

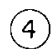

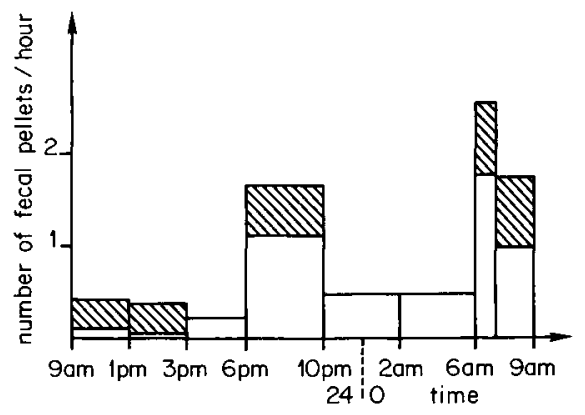

FIG. 3. - Mean number of fecal pellets ( \pm SEM) found in the stomach of rats eating a single meal and killed in lots of 4 each. The dashed lines are the clearance kinetics of the pellets after they passed into the small intestine; the clearance rate previously calculated for feeding (see fig. 2) has been applied to the pellets. Points $A$ and $B$ are, respectively, the number of pellets truly present at a given time and the number calculated using the above hypothesis.

FIG. 4. - Circadian rhythm of mean pellet elimination (without SEM) in rats ingesting a single daily meal. The white surfaces represent the pellets found on the bottom of the cages; hatched areas are the pellets eaten by the rat. 
(22 pellets/day), admitting that the number of pellets eliminated was proportional to food intake. Thus, the fecal excretion of restricted rats would not be quantitatively modified compared to that of the controls, but the restricted rats showed less coprophagy ( $29 \%$ of the eliminated pellets were ingested) than that observed in the controls $(41 \%)$. Curiously, the rhythm of fecal elimination in these two types of rat was similar (fig. 4). In fact, the major part of the pellets was eliminated between 6 and 10 p.m. and 6 and 9 a.m. In the controls, these events seemed to be triggered by food intakes (synchronizers) corresponding to the two main daily meals (Chevallier et al., 1974 ; Lutton and Chevallier, 1973). However, restricted rats continued to eliminate fecal pellets at the beginning of the dark period, although the meal usually given at that time was omitted. Light variation, which was almost concomitant with these various events (beginning of twilight at 7: 30 p.m.), thus might be an important factor in determining the fecal elimination of each rat.

\section{Cholesterol renewal.}

The 8 rats used for this study reached $427 \pm 4 \mathrm{~g}$ at the end of the experiment. Plasma concentrations of free and esterified cholesterol and free cholesterol in liver $10.27 \pm 0.1 \mathrm{mg} / \mathrm{ml} ; 0.64 \pm 0.01 \mathrm{mg} / \mathrm{ml} ; 1.52 \pm 0.06 \mathrm{mg} / \mathrm{g}$, respectively) were not significantly different from those observed in rats with no restricted rhythm of food intake (Magot et al., 1983). Only the concentration of liver esterified cholesterol was clearly different, being lower than that of the controls $(0.32 \pm 0.06 \mathrm{mg} / \mathrm{g}$ vs $1.19 \pm 0.19 \mathrm{mg} / \mathrm{g})$.

The fact that the food was practically all ingested in one single meal (between 6 and 7 a.m.) suggests an increase in the amplitude of the circadian rhythms, previously described in relation to the transformation of cholesterol into bile acids or to cholesterol synthesis (Chevallier and Lutton, 1966 ; Edwards et al., 1972). This is why half the rats were killed for the isotopic equilibrium experiment at $9: 30 \mathrm{a} . \mathrm{m}$. and the other half at $5: 30 \mathrm{p.m}$. The mean specific activity of free cholesterol in rats of the first group $\left(4080 \pm 110 \mathrm{dpm} / \mathrm{mg}\right.$ for ${ }^{14} \mathrm{C}$-cholesterol, $92460 \pm 2630$ for ${ }^{3} \mathrm{H}$-cholesterol) was lower than that of rats of the second group $\left(5260 \pm 250 \mathrm{dpm} / \mathrm{mg}\right.$ and $104230 \pm 730$ for ${ }^{14} \mathrm{C}$ and ${ }^{3} \mathrm{H}$, respectively). The difference $(29$ and $13 \%)$ was significant at the probability threshold ( $p \leq 0.01$ ). Such a difference suggests that the flow of synthetic cholesterol (not labelled in the isotopic equilibrium experiments) was higher shortly after food intake than $8 \mathrm{~h}$ later. Although this difference was sought for previously in the control rats, it was not found (Chevallier and Lutton, 1966).

The specific radioactivity of mobile cholesterol being a basic element in calculating the various flows responsible for cholesterol turnover, the values obtained by choosing the specific radioactivity of rats killed at $9: 30$ a.m. were higher than those of rats killed at $5: 30$ p.m. (table 1). We recall that the specific activity of mobile cholesterol has been previously defined by the mean of specific activities of free cholesterol from plasma, liver and red cells and of esterified cholesterol from plasma and liver. Considering the mean time separating the intake of food from its absorption, the values at $9: 30$ a.m. must be close to the maximal ones of the circadian cycle. On the contrary, the flows at $5: 30$ p.m. 
TABLE 1

Effects of a single daily meal on the mean flows $(\mathrm{mg} /$ day \pm SEM) of the processes invo/ved in cholesterol renewal and on the absorption coefficient of dietary cholesterol (in \%).

\begin{tabular}{|c|c|c|c|c|}
\hline & Controls & \multicolumn{3}{|c|}{ Restricted } \\
\hline Number of rats & 6 & \multicolumn{3}{|c|}{8} \\
\hline Method of calculation & a & a & & b \\
\hline 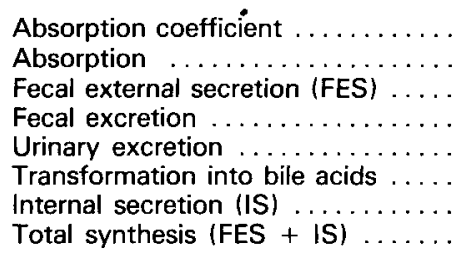 & $\begin{aligned} & 73.3 \pm 1.9 \\
& 6.6 \pm 0.3(2.2)^{\mathrm{c}} \\
& 4.1 \pm 0.2 \\
& 3.4 \pm 0.2(2.8)^{\mathrm{c}} \\
& 0.7 \pm 0.1 \\
& 14.5 \pm 0.5(11.3)^{\mathrm{c}} \\
& 12.7 \pm 0.4 \\
& 16.8 \pm 0.8\end{aligned}$ & $\begin{aligned} & 77.7 \pm 0.005 \\
& 2.2 \pm 0.005 \\
& 2.9 \pm 0.06 \\
& 3.1 \pm 0.08 \\
& 0.8 \pm 0.02 \\
& 14.7 \pm 0.4 \\
& 16.5 \pm 0.5 \\
& 19.4 \pm 0.5\end{aligned}$ & $\begin{array}{l}79 \\
2.2 \\
3.2 \\
2.75 \\
0.7 \\
11.5 \\
12.8 \\
16\end{array}$ & $\begin{array}{l} \pm 0.006 \\
\pm 0.01 \\
\pm 0.02 \\
\pm 0.02 \\
\pm 0.005 \\
\pm 0.6 \\
\pm 0.6 \\
\pm 0.6\end{array}$ \\
\hline
\end{tabular}

(a) Calculations using specific radioactivity of mobile cholesterol in rats killed at $9: 30$ a.m.

(b) Calculations using specific radioactivity of mobile cholesterol in rats killed at $5: 30 \mathrm{p} . \mathrm{m}$.

(c) Corrected value considering the difference in dietary cholesterol concentration (see text).

The methods for calculating these various flows have already been published (Lutton and Chevallier, 1972).

might not correspond to minimal circadian flows since there still remained $12 \mathrm{~h}$ and $30 \mathrm{~min}$ before intake began the following day. In conclusion, whiie the mean 24-h flows of restricted rats probably fell between those of rats killed at $9: 30$ a.m. and those killed at $5: 30$ p.m., they were certainly very similar to the flows obtained in the second group of rats. Moreover, these flows were practically equal to those of the controls in view of the following fact (table 1) : cholesterol concentration in the diet of the control rats was about 3 times higher than that in the diet of the experimental rats (Magot et al., 1983). The absorption coefficients being about equal, it follows that the flow of absorption was $6.6 \mathrm{mg} /$ day in the first case and $2.2 \mathrm{mg} /$ day in the second. However, increasing this flow caused modifications in some other flows, which may be logical. In fact, on the one hand the synthetic flows showed little change, considering the variation in the flow of exogenous cholesterol (Mathé and Chevallier, 1979), and, on the other hand, about $80 \%$ of the cholesterol, whatever its origin, was excreted in the form of bile acids, the rest being eliminated mainly as excreted cholesterol (Mathé and Chevallier, 1980). The values of the flows of transformation and excretion calculated after these observations should be 11.3 and $2.8 \mathrm{mg} /$ day, respectively, for control rats absorbing $2.2 \mathrm{mg} /$ day. A comparison of the values (circadian means) of restricted rat flows and those of the corrected flows of the controls clearly shows that the dynamics of the cholesterol system is practically the same in both groups of rats. 
Résumé. Influence d'une alimentation quotidienne en temps limité sur le poids, le transit digestif et le renouvellement du cholestérol de rats adultes.

Des rats ont été entraînés à ingérer un seul repas solide quotidien de $15 \mathrm{~g}$ entre $6 \mathrm{gt}$ $9 \mathrm{~h}$. En fait, ils n'ingèrent en moyenne que $14,4 \mathrm{~g}$ dont $90 \%$ durant la première heure. On a vérifié que cette valeur définit la capacité volumique moyenne des estomacs pleins des rats, dont le poids se stabilise rapidement à $402 \pm 2 \mathrm{~g}$, valeur précédemment obtenue avec un même apport alimentaire quotidien étalé durant le nycthémère selon le rythme spontané classique. La contrainte imposée ne modifie pas le nombre de crottes émises ; par contre, la coprophagie est réduite $(29 \%$ de l'émission totale au lieu de $41 \%)$. Il est curieux de constater que le rythme de l'émission fécale est le même chez les rats contraints et les témoins. Cette observation suggère l'importance de la lumière comme synchronisateur de cette émission, alors que ce rôle était imputé précédemment aux prises alimentaires. Enfin, la vidange gastrique du rat s'effectue, comme chez l'homme et le porc, selon une fonction mono-exponentielle dont le $t_{1 / 2}$ est d'environ 4 heures.

D'autre part, le système cholestérol a été exploré à l'aide de la méthode d'équilibre isotopique. Ajustées sur la durée d'un nycthémère, les valeurs des débits des divers processus de renouvellement du cholestérol sont sensiblement égales à celles des rats témoins. Mais la variation nycthémérale relative à la synthèse du cholestérol est plus accusée.

\section{References}

BLAIZOT S., 1979. Alimentation en temps limité (" meal feeding ») et avitaminose A : échanges respiratoires et adaptation métabolique du rat. Ann. Nutr. Alim., 33, 363-383.

CHEVALLIER F., LUTTON C., 1966. Cinétique journalière et horaire de la transformation du cholestérol $26-{ }^{14} \mathrm{C}$ en acides biliaires. Bull. Soc. Chim. biol., 48, 295-311.

CHEVALLIER F., LUTTON C., 1966. Vitesse des processus de renouvellement du cholestérol contenu dans son espace de transfert, chez le rat. I. Méthodes et résultats obtenus dans le cas d'un régime semi-synthétique témoin. Bull. Soc. Chim. biol., 48, 507-524.

CHEVALLIER F., LUTTON C., CHAMPARNAUD C., 1974. Cycles et profils d'activité du rat blanc au cours du nycthémère définis par le débit de son $\mathrm{CO}_{2}$. Rev. Compor. anim., 8, 127-145.

CHEVAlLIER F., SEROUgNe C., CHAMPARNAUD G., 1975. Effect upon brain weight and cholesterol content of maintaining rats of various ages at constant weight. J. Nutr., 105, 1003-1011.

EDWARDS P. A., MUROYA H., GOULD R. G., 1972. In vivo demonstration of the circadian rhythm of cholesterol biosynthesis in the liver and intestine of the rat. J. Lipid Res., 13, 396-401.

FULLER R. W., DILLER E. R., 1970. Diurnal variation of liver glycogen and plasma free fatty acids in rats fed ad libitum or single daily meal. Metabolism, 19, 226-229.

HUNT J. N., SPURELL W. R., 1951. The pattern of emptying of the human stomach. J. Physiol., 113, 157-168.

KAUL L., BERDANIER C. D., 1977. Effect of meal feeding on the daily variations of insulin, glucose and NADP linked dehydrogenases in rats. J. Nutr., 107, 746-757.

LAPLACE J. P., TOMASSONE R., 1970. Evacuation gastroduodénale chez le porc: fistulation chronique par. voie extra-pleurale; recherche d'une technique d'analyse mathématique de l'évacuation. Ann. Zootech., 19, 303-332.

LEVEILLE G. A., CHAKRABARTY K., 1967. Diurnal variations in tissue glycogen and liver weight of meal fed rats. J. Nutr., 93, 546-554.

LEVEILLE G. A., OHEA E. K., 1967. Influence of periodicity of eating on adipose tissue metabolism in the rat. J. Nutr., 93, 541-545. 
LUTTON C., CHEVALLIER F., 1972. Vitesses des processus de renouvellement du cholestérol contenu dans son espace de transfert chez le rat. III. Modification et étude critique de la méthode d'équilibre isotopique. Biochim. Biophys. acta, 255, 762-779.

LUTTON C., CHEVALLIER F., 1973. Coprophagie chez le rat blanc. Aspects quantitatifs et relation chronologique avec les prises alimentaires. J. Physiol., 66, 219-228.

MAGOT T., CASTAING G., MATHÉ D., BISMUTH M., CHEVALLIER F., 1983 . Effect of portacaval or mesenterico-caval anastomosis on cholesterol metabolism in rats. Atherosc/erosis, 46, 77-86.

MATHÉ D., CHEVALLIER F., 1979. Effects of level of dietary cholesterol on the dynamic equilibrium of cholesterol in rats. J. Nutr., 109, 2076-2084.

MATHÉ D., CHEVALLIER F., 1980. Factors determining to biotransformation of cholesterol to bile acids in the rat. Digestion, 20, 121-136.

MATHÉ D., LUTTON C., RAUTUREAU J., COSTE T., GOUFFIER E., SULPICE J. C., CHEVALLIER F., 1977. Effects of dietary fiber and salt mixtures on the cholesterol metabolism of rats. J. Nutr., 107, 466-474.

RÉRAT A., LOUGNON J., 1963. Etudes sur le transit digestif chez le porc. Ann. Biol. anim. Bioch. Bioph., $\mathrm{n}^{\circ} 3$ (hors série), 21-27. 